Article

\title{
Assessment of Methods for Forecasting Shale Gas Supply in China Based on Economic Considerations
}

\author{
Xiaoqian Guo ${ }^{1,2}$ (D), Qiang Yan ${ }^{1,2}$ and Anjian Wang ${ }^{2, *}$ \\ 1 MLR Key Laboratory of Metallogeny and Mineral Assessment, Institute of Mineral Resources, \\ China Academy of Geological Science, Beijing 100037, China; xiaoqianGuo88@163.com (X.G.); \\ cagsyq@163.com (Q.Y.) \\ 2 Research Center for Strategy of Global Mineral Resources, Institute of Mineral Resources, \\ China Academy of Geological Science, Beijing 100037, China \\ * Correspondence: ajwang@126.com; Tel.: +86-010-6899-9066
}

Received: 25 September 2017; Accepted: 26 October 2017; Published: 30 October 2017

\begin{abstract}
Shale gas, with its lower carbon content and pollution potential, is the most promising natural gas resource in China. When modeling the shale gas supply in a specific gas field, it is of paramount importance to determine the gas supply under economic considerations. Two common calculation methods are used in China for this purpose: Method 1 (M1) is the breakeven analysis, where the gas supply is based on the relationship between costs and revenues, while Method 2 (M2) is the Geologic Resource Supply-Demand Model, where the supply relies on demand and price scenarios. No comparisons has been made between these two methods. In this study, the Fuling shale gas field in the Sichuan Basin was chosen as a study case to forecast the shale gas supply using these two different methods. A sensitivity analysis was performed to discuss the influencing factors of each method and error measures were used to compare the different shale gas supply values calculated by each method. The results shows that M1 is more sensitive to initial production, while M2 is more sensitive to gas price. In addition, M2 is more feasible for its simplicity and accuracy at high price scenarios and M1 is considered to be reliable for low price scenarios with profit. This study can provide a quick and comprehensive assessment method for the shale gas supply in China.
\end{abstract}

Keywords: China; shale gas; supply; economic consideration

\section{Introduction}

In recent years, air pollution, mostly caused by the fossil energy consumption, has received significant attention from the Chinese government. Natural gas with lower carbon content and pollution potential has been chosen as a main clean energy substitute in China's 13th Five-Year Plan. China's annual natural gas primary consumption is supposed to increase with a growth rate of $19 \%$, and the proportion of gas in energy consumption structure will rise to $10-15 \%$ from $5.6 \%$ in 2014 , with a total volume up to 350 billion cubic meters [1]. Therefore, the demand for natural gas has increased significantly in China and this will bring many changes in the natural gas industry. Among all the conventional and unconventional natural gas sources, shale gas is the most promising natural gas resource in China. Reports about shale gas global technically recoverable resources (TRR) from the U.S. Energy Information Administration (EIA) show that China ranked No. 1 in the world in shale gas, with shale gas TRR of 1115 trillion cubic feet (31.57 trillion cubic meter) [2]. According to the resource estimation from the Ministry of Land and Resources (MLR), China's shale gas TRR are about 21.8 trillion cubic meter, with 44 prospecting rights and 144,000 cubic kilometer of favorable area [3]. The abundant shale gas resource in China augur a bright future for shale gas development.

Despite the abundant shale gas resources, there is a serious problem concerning the regional mismatch between the gas supply and demand, due to the regional unbalances in natural resource 
endowment and economy growth in China [4,5]. Most industrial shale gas is located in the Ordovician Wufeng-Lower Silurian Longmaxi Formation, which is mainly distributed in southern China, including the Sichuan Basin, eastern Chongqing and western Hubei, northern Yunnan and Guizhou, and western Hunan $[6,7]$. So far, it is known that the Wufenge Longmaxi Formation is very rich in shale gas resources, featuring wide gas distribution and high production over a large area, whereas in northern China, there are relatively fewer shale gas resources. According to the previous research, China's natural gas demand will reach 315 billion cubic meters in 2020 [8]. In order to dispatch the available shale gas in a better way, construction of a series of pipeline networks and gas power plants around shale gas fields has become necessary in recent years [9]. Since all these construction projects will depend greatly on the shale gas production, the evaluation of economic shale gas supply is a paramount goal.

A number of contributions have addressed the calculation of shale gas supply. Breakeven analysis, Hubbert curves, EIA's National Energy Models (NEMS) and supply-demand models are the widely used methods to forecast gas supply. Breakeven analysis relies on the Net Present Value (NPV) model and economic supply is determined by the relationship between cost and revenue [10-12]. The NPV model has been widely used for both fossil fuel and mineral resources with different variables [13]. Hubbert curves are the most influential single equation model to discuss the peak and lifetime production for fossil fuels [14]. The EIA NEMS model contains both supply and demand factors and a price of resources, taking into account new discoveries in reserves [15]. Geologic Resource Supply-Demand Model (GeRs-DeMo), which includes both static and dynamic models, has been successfully used to project the long-term production of unconventional hydrocarbons [16].

Among these models, breakeven analysis and GeRs-DeMo are widely used to predict the shale gas supply in a specific field in China. Breakeven analysis has been used for calculating economic critical depth and evaluating economic oil and gas production in the short term [17]. Detailed and numerous cost data from each exploitation stage for a single well will be collected to decide the economic supply. The static model in GeRs-DeMo with no interaction between supply and demand is used to forecast China unconventional gas production [18] and different price scenarios are chosen to simulate the production change [19].

The goal of this paper is to provide a range of estimates of shale gas supply by these two widely used methods in the hope that we can give a more reliable and convenient method to estimate the shale gas supply in a certain field. Both breakeven analysis and GeRs-DeMo methods have their shortcomings and advantages in forecasting. During breakeven analysis (M1 in this research), numerous data will be collected, which may be difficult in China's current early shale gas development stage. Compared to M1, the gas supply calculation in GeRs-DeMo (M2 in this research) is more feasible for its simplicity. However, M2 relies on the price scenario, which is hard to project. Since shale gas industrial production has already started in Fuling, in the Sichuan Basin in China, this shale field was chosen as a case study with relatively complete data sources. Sensitivity analysis will be made on each method to see the controlling factors and the difference and similarity will be discussed through error measures. In addition, suggestions will be provided regarding the better method under different scenarios.

\section{Methods for Shale Gas Supply Calculation}

\subsection{Breakeven Analyses for Shale Gas Supply}

Shale gas prediction by breakeven analysis is the reverse calculation of NPV. NPV is one of the most reliable economic indicators for analyzing the profitability of an investment. A positive NPV implies that investment in a shale gas resource will add value to the firm, thus making it worthy of 
exploitation. Otherwise, a negative $N P V$ for a projection means investment should be discarded, so the basic shale gas supply will be guaranteed at the point of zero NPV. NPV can be expressed as:

$$
N P V=\sum_{k=1}^{K}(C I-C O)\left(1+i_{0}\right)^{-k}
$$

where $C I$ is the cash inflow, mostly consisting of cost components, $C O$ is the cash outflow, consisting of revenue, $k$ is the development year of shale play, $i_{0}$ is the discount rate and $K$ is the whole development years of the shale play. The whole workflow of M1 is shown in Figure 1 and the cost components and revenue are listed.

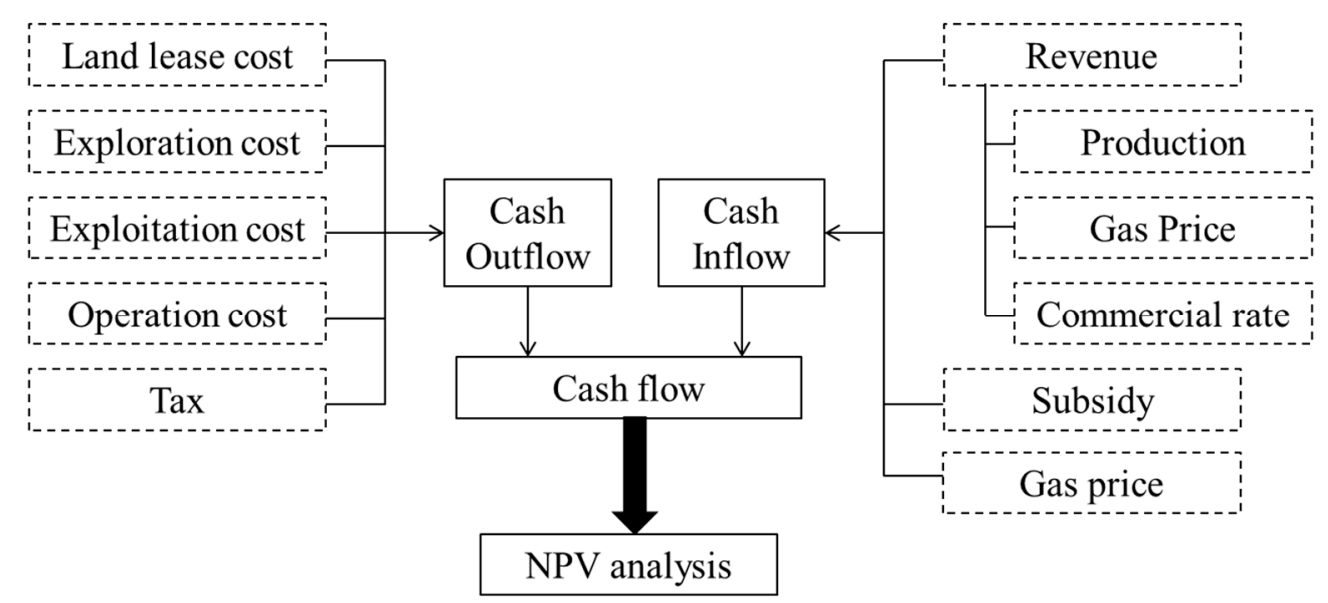

Figure 1. Workflow of breakeven analysis.

\subsubsection{Cost Components}

Because of the socialist public ownership of land, land cannot be traded as an object in China. Only the use right of land can be transferred. Therefore, the land acquisition cost is the lease cost, paid to the landowner or constructor [20]:

$$
C_{L}=A \cdot c_{l a}
$$

$A$ is the occupied leasing area $\left(\mathrm{km}^{2}\right)$, and $c_{l a}$ is the average leasing cost of target land, determined by the Chinese government.

During the shale gas exploration, the cost is mainly from two parts, the seismic and exploration wells. Seismic wells consist of two-dimensional (2D) seismic and three-dimensional (3D) seismic wells:

$$
C_{S}=C_{S 2 D}+C_{S 3 D}=c_{s 2 d a} \cdot n_{S}+c_{s 3 d a} \cdot A_{S 3 d}
$$

For a single well, the exploration well cost includes drilling cost, well logging cost, core lab test cost and reservoir characterization cost. Generally, the exploration well costs are divided into two parts for calculation convenience, fixed cost $\left(c_{\text {ewf }}\right)$ and depth-related cost $\left(c_{e w a}\right)$, so the exploration well cost is:

$$
C_{E W}=c_{e w f}+c_{e w a} \cdot d
$$

Drilling and completion (D \& C) cost are usually the main part of cost for the producing well. The D \& C cost includes drilling equipment leases, logging while drilling (LWD), drilling fluids and other costs. The D \& C cost for a single well can also consist of a depth-related part and fixed part. Most shale gas wells are horizontal wells, so the depth-related part contains vertical parts $(d)$ and horizontal parts $(l)$. The whole D \& C cost is:

$$
C_{D C}=c_{d c f}+c_{d c v a} \cdot d+c_{d c h a} \cdot l
$$


Hydraulic fracturing is considered to be a necessary step to enhance the shale gas recovery. According to production reports from the Fuling field, staged fracturing is widely used in China and the whole cost for hydraulic fracturing is related to the number of stages $\left(N_{f_{s}}\right)$ [21-23]:

$$
C_{H F}=c_{h f a} \cdot N_{f s}
$$

Operation cost for shale gas wells usually means the labor, maintenance of surface facilities, repairs, water disposal and gas processing and transport costs. These costs usually fall into the categories of fixed and variable costs. The variable costs such as labor, water disposal and gas processing are calculated based on the production volume $(Q)$, so the operation cost is:

$$
C_{O P}=c_{o p f}+c_{o p a} \cdot Q
$$

In China shale gas is taxed like natural gas, including resource tax, education and construction tax, corporate income tax and value-added tax, while the resource compensation tax and mining use right are exempted. The resource tax, education and construction tax and value-added tax are calculated on the gas sale revenue. The corporate income tax is calculated on revenue with deduction of capital cost and amortization, so the gas tax is:

$$
T=R_{\text {gas }} \cdot\left(r_{a d}+r_{c o n}+r_{e d u}+r_{r e s}\right)+\left(R_{g a s}-C_{O P F}-C_{d e p}\right) \cdot r_{i c}
$$

$R_{\text {gas }}$ is the total shale gas revenue, $r_{a d}, r_{c o n}, r_{\text {edu }}, r_{\text {res }}, r_{i c}$ are the added value tax, construction tax, education tax, resource tax and corporate tax. $C_{O P F}$ and $C_{d e p}$ is the capital cost and amortization cost.

\subsubsection{Revenue}

Shale gas revenue usually depends on the gas price $\left(p_{\text {gas }}\right)$, gas production volume, commercialization rate $\left(r_{\text {com }}\right)$ and fix assets recycle $\left(r_{\text {fix }}\right)$. In China, shale gas producers can also get subsidy from the Chinese government. The subsidy for shale gas varies every 5 years, along with each five-year plan. During 2010-2015, the shale gas subsidy was $0.5 \mathrm{RMB} / \mathrm{m}^{3}$ and during 2015-2020, the subsidy will be $0.3 \mathrm{RMB} / \mathrm{m}^{3}$ for the first three years and $0.2 \mathrm{RMB} / \mathrm{m}^{3}$ for the last two years [24], so the shale gas revenue is:

$$
R=\left(p_{g a s}+s\right) \cdot Q \cdot r_{c o m}+r_{f i x}
$$

\subsubsection{Production Profile}

Estimation of natural gas production from a single well is an important issue. Usually, reservoir simulation and decline curve analysis are two common methods for production prediction. For the whole shale gas field, reservoir simulation is not a realistic option due to the lack of understanding of reservoir physics characters. Therefore, the decline curve analysis is widely used in shale gas economic models. The most commonly used trending equation is the on first documented by Arps, the Arps decline curve $[25,26]$. The general form of Arps' suggested decline curve is:

$$
q=q_{i} \frac{1}{\left(1+b D_{i} t\right)^{1 / b}}
$$

For most shale gas wells, the production decays at a quick rate, so new wells have to be drilled every year to keep the whole gas production in play. The whole gas production in a shale play consists of production from both new wells $\left(n_{k-2}\right)$ and old wells $\left(B_{k}\right)$. Since most producing wells begin to provide continuous gas production two years after drilling, the gas production is:

$$
T Q_{i}=\sum_{k=1}^{k} n_{k-2} Q_{k-2}+B_{k}
$$




\subsection{4. $N P V(Q)$ function for production}

When all the cost and revenue components were listed, substituting them into Equation (1) using the workflow outlined in Figure 1 gives the final expression for $N P V(Q)$ [17]:

$$
N P V(Q)=\sum_{k}\left(R_{K_{B} \leq k \leq K}-\left(C_{L}\right)_{k=1}-\left(C_{S}+C_{E W}\right)_{2 \leq k \leq K_{E}}-\left(C_{D C}+C_{H F}+C_{o p}+T\right)_{K_{B} \leq k \leq K}\right)(1+i)^{-k}
$$

where $K_{E}$ de denotes the year at the end of development drilling phase; $K_{B}$ denotes the year at the beginning of the production phase. The term $Q$ will be solved when $N P V(Q)=0$. Since $N P V(Q)$ is a monotonic function, and $N P V(Q)=0$ can have only one root, which can be approximated by an iterative method through trial and error in a spreadsheet calculation.

\subsection{Geological Resource Supply-Demand Model}

GeRS-DeMo deals with the long-term supply and demand in dynamic and static ways. In static mode, no interaction is set between supply and demand, while in dynamic model, the amount of supply is considered to be reduced if demand is low $[8,27,28]$. In this study, the static model is chosen because of the lack of enough data to support the estimation of the impact of the environment, policy and other factors on the demand reduction. The natural gas demand in China during the next few decades can be considered to be inadequate according to the huge gap between consumption and production of natural gas in recent years shown in Figure 2. All the consumption, export and production data are from National Bureau of Statistics of the People's Republic of China.

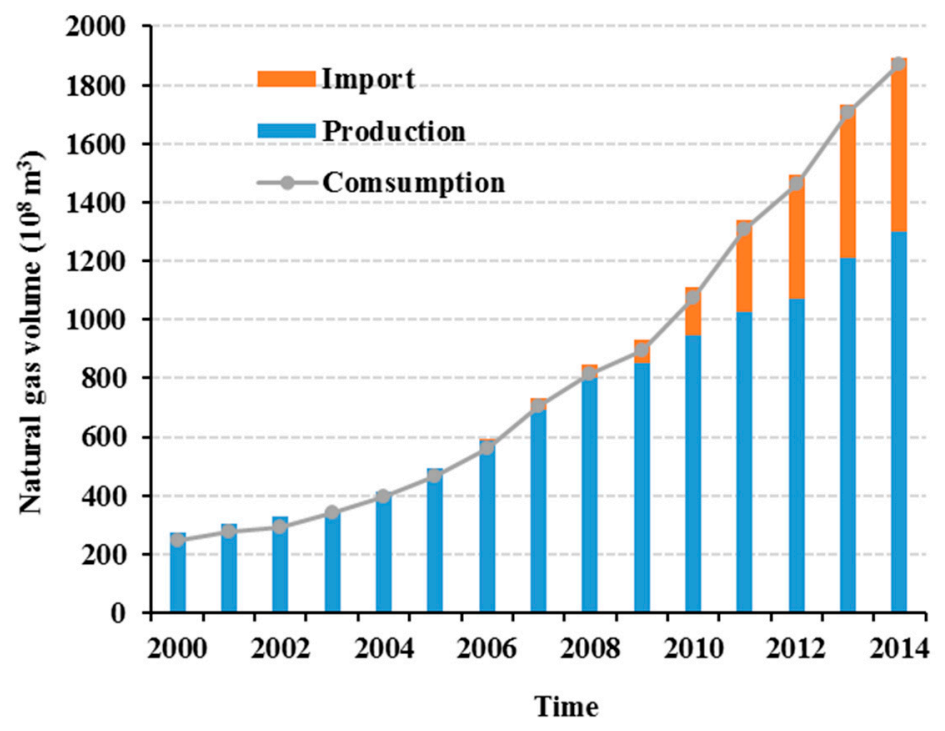

Figure 2. Natural gas import, production and consumption situation in China.

In the static model, the production for a particular oil and gas field is calculated based on one important input parameter, ultimately recoverable resources (URR). URR represent the total amount of shale gas economic and technological extraction over time and represent the long-term shale gas supply in this field. Since economic limits have been proved to affect the oil and gas extraction, and high price will encourage the oil and gas supply, so a scenario analysis is used in this study and we set three different price scenarios: reference case, high price case and low price case, based on the EIA study considering economic limits shown in Figure 3 [29]. 


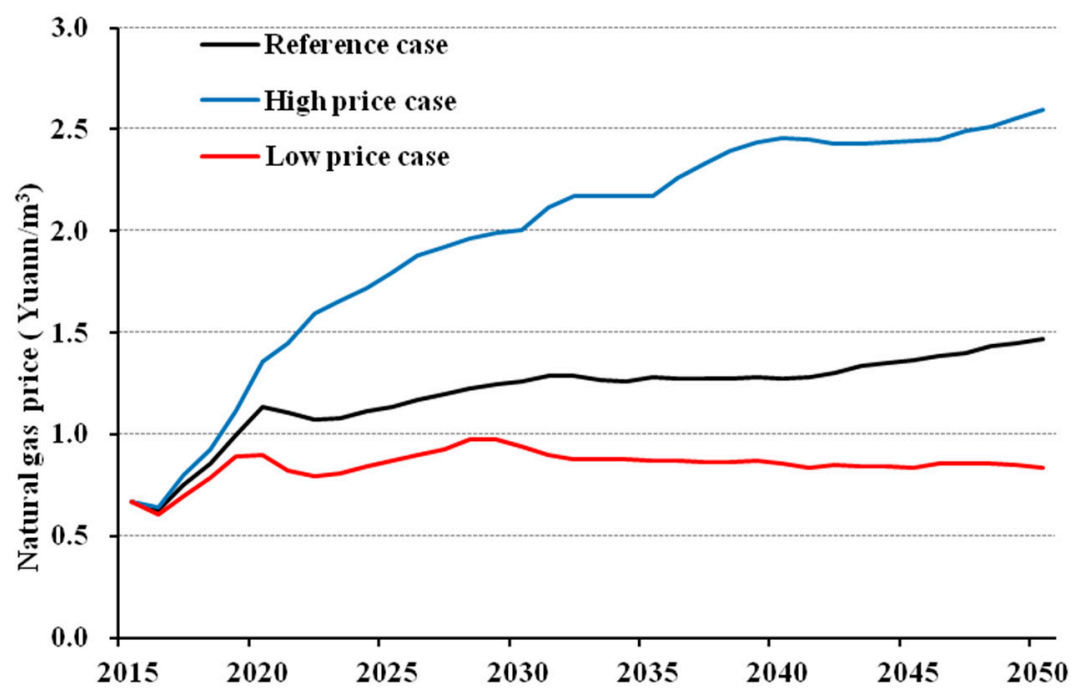

Figure 3. Price scenarios for shale gas (adapted from the EIA Annual Energy Outlook 2017).

Available methods for forecasting the natural gas production year-by-year based on the estimate URR include the Hubbert Model, Generalized Wang Model, the HCZ Model and the Resource-Constrained Growth Model [30]. Since there is not enough historical data for shale gas in China, the Resource-Constrained Growth Model (RCGM) is used in this study. Wang et al. gives a brief introduction to RCGM method and Equations (13) and (14) show the main equations in this model:

$$
\begin{gathered}
q(t)=q_{0} e^{k r t}\left(1-\frac{Q(t)}{U R R}\right) \\
k \approx \frac{\ln \left[(1+r)^{t_{1}} /\left(1-\left(\frac{q_{0}\left(1+(1+r)^{t_{1}}\right.}{2 \mathrm{URR}}\right)\right]\right.}{r t_{1}}
\end{gathered}
$$

In this model, $k$ is an exponent factor used to force the model to yield exponential growth. More detailed information about this description can be found in the Ward study [31].

\section{Case Study}

\subsection{Description}

The Fuling shale gas field, with geological resources of approximate 2000 billion $\mathrm{m}^{3}$, was operated by Sinopec in the Sichuan Basin after the successful commercial rate production was tested on the Silurian Longmaxi marine shale. The technical recoverable resource (TRR) are 195.4 billion $\mathrm{m}^{3}$, with a burial depth above $4500 \mathrm{~m}$ underground [32-34].

Since shale gas development in Fuling is in its initial stage, the production rate and initial production of a single well described in different references and reports are collected. According to the published research $[35,36]$ and related production reports from Sinopec, the average production profiles with different initial production (IP) are computed in Figure 4 and denoted by P10, P50 and P90, which represent the well profile where $10 \%, 50 \%$ and $90 \%$ of all wells within the sample exceed its cumulative production, respectively. The initial production, decline rate and URR for single well of each type is shown in Table 1. For the shale gas well cost in Fuling, the data reference was from two sources: (1) official reports and news, mainly from MLR and Sinopec; (2) high quality published papers and study reports. 


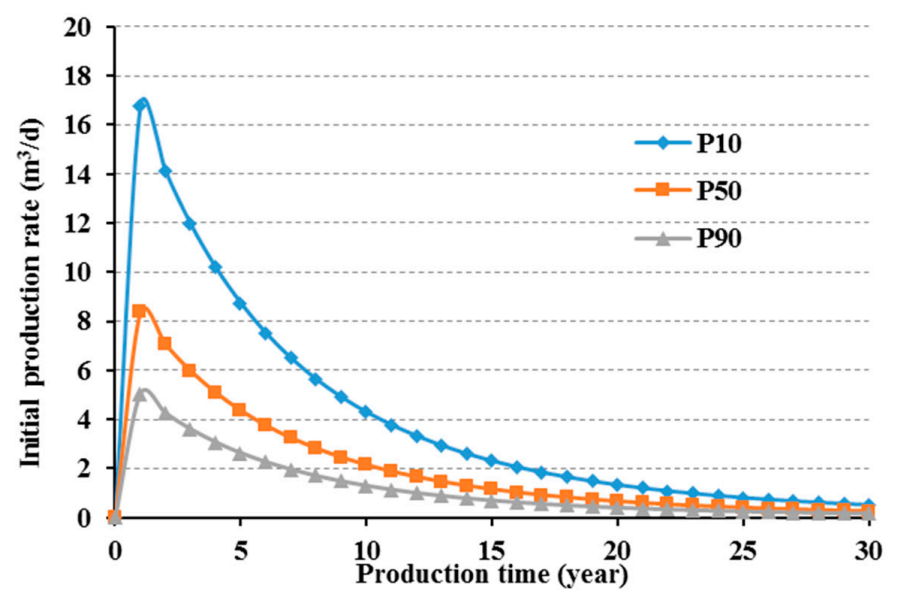

Figure 4. Average production profile in the Fuling field.

Table 1. Production class and well performance for Fuling field.

\begin{tabular}{cccc}
\hline \multirow{2}{*}{ Profile } & IP & Decline Rate & URR for Single Well \\
\cline { 2 - 4 } & $\mathbf{1 0}^{\mathbf{6}} \mathbf{~}^{\mathbf{3}}$ & N/A & $\mathbf{1 0}^{\mathbf{8}} \mathbf{~}^{\mathbf{3}}$ \\
\hline P10 & 0.05 & 0.6 & 1.10 \\
P50 & 0.10 & 0.6 & 1.83 \\
P90 & 0.15 & 0.6 & 3.66 \\
\hline
\end{tabular}

The cost components for Fuling field are listed in Table 2 and the relevant sources are listed in the notes. The gas supply by M1 will be calculated through the equations given in Section 2.1 with the following data.

Table 2. Key factors for cost component calculation in the Fuling field.

\begin{tabular}{|c|c|c|c|c|}
\hline \multicolumn{2}{|r|}{ Cost Components } & \multirow{3}{*}{$\begin{array}{c}\text { Notation } \\
A \\
c_{l a} \\
\end{array}$} & \multirow{3}{*}{$\begin{array}{c}\text { Unit } \\
\mathrm{km}^{2} \\
\text { Yuan } / \mathrm{km}^{2}\end{array}$} & \multirow{3}{*}{$\begin{array}{c}\text { Value } \\
600 \\
2.54 \times 10^{6}\end{array}$} \\
\hline & Area of land occupied & & & \\
\hline Land lease & Land lease & & & \\
\hline \multirow{6}{*}{ Exploration } & Average cost of $2 \mathrm{D}$ seismic & $c_{S 2 d a}$ & Yuan $/ \mathrm{km}$ & $1.0 \times 10^{5}$ \\
\hline & Length of seismic line & $l_{s}$ & $\mathrm{~km}$ & 60 \\
\hline & Average cost of 3D seismic & $c_{S 3 d a}$ & Yuan $/ \mathrm{km}^{2}$ & $5 \times 10^{5}$ \\
\hline & Area of 3D seismic & $A_{s 3 d}$ & $\mathrm{~km}^{2}$ & 400 \\
\hline & Fixed cost of exploration well & $c_{\text {ewf }}$ & Yuan & $2.5 \times 10^{6}$ \\
\hline & Average cost related to depth & $c_{\text {ewa }}$ & Yuan/m & $5 \times 10^{3}$ \\
\hline \multirow{3}{*}{$\mathrm{D} \& \mathrm{C}$} & Fixed D \& C cost per well & $C_{d c f}$ & Yuan & $6.8 \times 10^{5}$ \\
\hline & Average cost related to vertical part & $c_{d c v a}$ & Yuan/m & $5 \times 10^{3}$ \\
\hline & Average cost related to horizontal & $c_{d c h a}$ & Yuan/m & $8 \times 10^{3}$ \\
\hline Hydraulic fracture & hydraulic fracture cost for each stage & $C_{h f a}$ & Yuan/stage & $6.8 \times 10^{4}$ \\
\hline \multirow{2}{*}{ Operation } & Fixed cost of operation & $c_{\text {opf }}$ & Yuan & $9 \times 10^{4}$ \\
\hline & average operation cost per gas unit & $c_{\text {opa }}$ & Yuan $/ \mathrm{m}^{3}$ & 0.3 \\
\hline \multirow{5}{*}{ Tax } & add value tax & $r_{a d}$ & $\mathrm{~N} / \mathrm{A}$ & $11 \%$ \\
\hline & construction tax & $r_{\text {con }}$ & $\mathrm{N} / \mathrm{A}$ & $7 \%$ \\
\hline & education tax & $r_{e d u}$ & $\mathrm{~N} / \mathrm{A}$ & $5 \%$ \\
\hline & resource tax & $r_{\text {res }}$ & $\mathrm{N} / \mathrm{A}$ & $5 \%$ \\
\hline & corporate tax & $r_{i c}$ & $\mathrm{~N} / \mathrm{A}$ & $25 \%$ \\
\hline
\end{tabular}

The gas supply by method M2 is based on scenario analysis and three scenarios are set in this study. The reference case can represent the best estimation. The prices will keep rising in a suitable range based on predictable factors, such as environmental considerations, policies and others $[18,37]$. 
The URR in this scenario are assumed to be $50 \%$ of the total amount of technically recoverable resources (TRR), since the perspective exploration and exploitation of shale gas in the Sichuan Basin. The second scenario is the high price case and the price will keep rising to a high level. This scenario can be regarded as an upper boundary for the production growth and we set that $80 \%$ of the shale gas TRR will be extracted due to the development of new technology encouraged by a high price. The last scenario is the low price case and $20 \%$ of the shale gas TRR will be extracted. The URR under different price scenarios were listed in Table 3.

Table 3. Resources estimation under different scenarios for Fuling.

\begin{tabular}{cccc}
\hline Resources & Reference Case & High Price Case & Low Price Case \\
\hline Recovery ratio & $50 \%$ & $80 \%$ & $20 \%$ \\
URR $\left(10^{8} \mathrm{~m}^{3}\right)$ & 977 & 1563.2 & 390.8 \\
\hline
\end{tabular}

\subsection{Results}

In this study, we discuss three price scenarios and three IP conditions. Thus, nine combinations will be created with different IP and price scenarios. These nine combinations were: IP1-P1 (IP $=0.05 \mathrm{Mm}^{3}$, low price scenarios), IP1-P2 (IP $=0.05 \mathrm{Mm}^{3}$, reference price scenarios), IP1-P3 (IP $=0.05 \mathrm{Mm}^{3}$, high price scenarios), IP2-P1 (IP $=0.10 \mathrm{Mm}^{3}$, low price scenarios), IP2-P2 (IP $=0.10 \mathrm{Mm}^{3}$, reference price scenarios), IP2-P3 (IP $=0.10 \mathrm{Mm}^{3}$, high price scenarios), IP3-P1 (IP $=0.15 \mathrm{Mm}^{3}$, low price scenarios), IP3-P2 (IP $=0.15 \mathrm{Mm}^{3}$, reference price scenarios), IP3-P3 (IP $=0.15 \mathrm{Mm}^{3}$, high price scenarios). In order to discuss the differences of these two method under the same conditions, the gas supply is shown in the nine subfigures of Figure 5. Each subfigure matches each condition assumption. The supply curves on Figure 5 are consistent with previous studies on energy supply calculations $[17,18]$ and the peak time and peak production vary with different scenarios $[15,28]$.
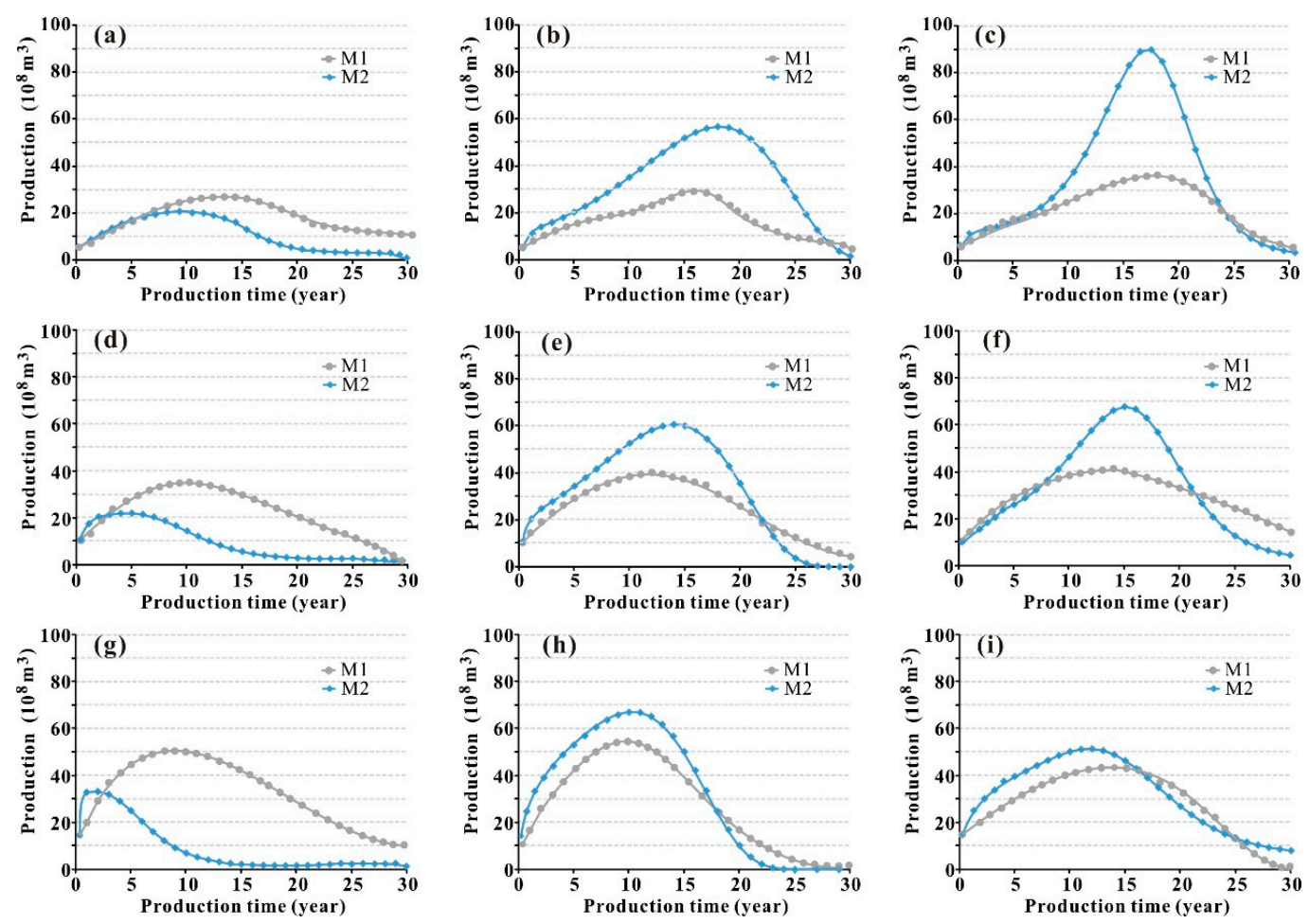

Figure 5. Gas supply by two different methods under different IP and price scenarios. (a) IP1-P1; (b) IP1-P2; (c) IP1-P3; (d) IP2-P1; (e) IP2-P2; (f) IP2-P3; (g) IP3-P1; (h) IP3-P2; (i) IP3-P3. 


\section{Discussion}

\subsection{Sensitivity Analysis}

Considering the high uncertainty and risk associated with shale gas development, it is necessary to conduct a sensitivity analysis. The purpose of sensitivity analysis is to investigate the effects of key factors on the final shale gas supply. The sensitivity coefficient factor is defined as the rate of changes for an uncertainty factor, and it can be expressed as:

$$
S_{c a}=\frac{\Delta x / x}{\Delta y / y}
$$

The $\Delta x / x$ is the rate change of the shale gas supply, while $\Delta y / y$ is the rate change of uncertainty factors. The calculation of gas supply can be affected by many factors [38,39]: geological factors, calculation time in economic models and others. In this study, IP and price are the two factors chosen, mainly representing the geological and economic effects. In order to quantify the change of shale gas supply, three parameters determining the character of shale gas supply were chosen: URR, peak time and peak production. When one of these three parameters changes, the whole supply curve will also change significantly.

The effect of IP and price on each key parameter of gas supply according to M1 is calculated and shown in Figure 6a. Compared to M2, M1 is more sensitive to IP with a higher sensitivity coefficient. In addition, the effects of these three parameters on M1 can be ranked according to the sensitivity coefficients as follows: URR, peak production and peak time. Thus, IP risk on the calculation by M1 can be easily identified and URR will change significantly with different IP profiles. Since M1 is riskier with variable IP, more attention should be paid in the M1 model when the shale gas field is in the initial stage with more IP profile uncertainty.

The IP and price sensitivity analysis were applied to the gas supply by M2 in Figure 6b. The sensitivity coefficients of price were higher than the IP, meaning that according to M2 the gas supply was more sensitive to price changes. Based on the sensitivity coefficients, URR is obviously more sensitive to the price change. This is related to its calculation methods described in Section 2.2 and the price will have a greater effect on URR with M2, so the estimation of future price change is vital for calculation by M2.

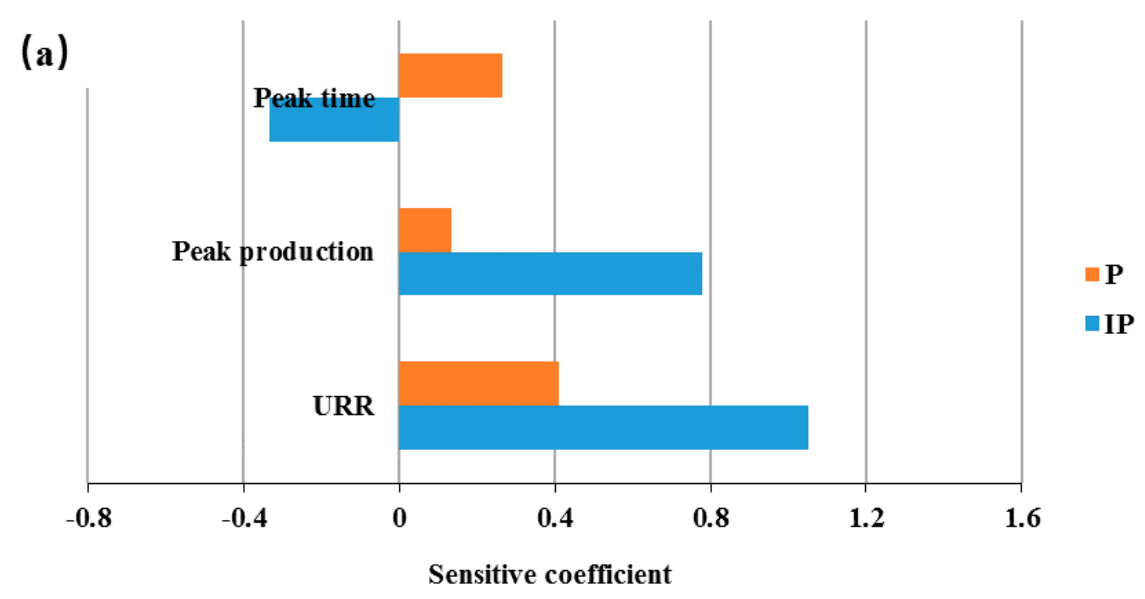

Figure 6. Cont. 


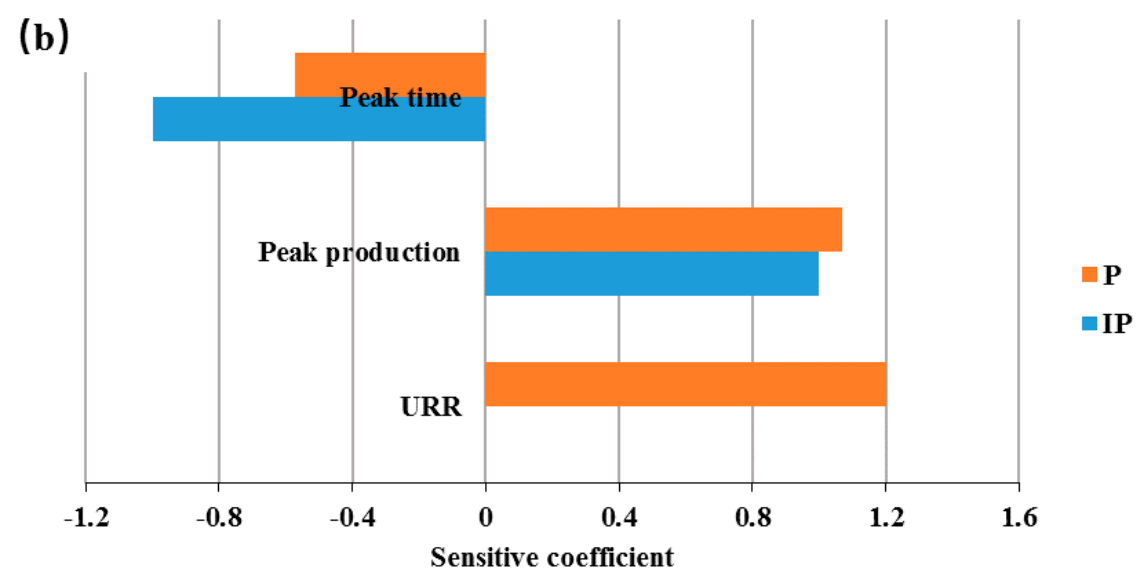

Figure 6. Sensitivity coefficient of IP and price on three key supply factors. (a) SA of gas supply by M1; (b) SA of gas supply by M2.

\subsection{Comparison of Shale Gas Supply from Two Methods}

To better observe the difference of gas supply by the two methods, correlation coefficient error measures were employed for evaluation and comparison. The correlation coefficient $(R)$ is used to characterize the similarity of the correlation between the data from these two methods:

$$
R=\frac{\sum\left(a^{(0)}(k) \cdot b^{(0)}(k)\right)-\frac{1}{n} \sum a^{(0)}(k) \cdot \sum b^{(0)}(k)}{\sqrt{\left[\sum\left(a^{(0)}(k)\right)^{2}-\frac{1}{n} \sum\left(a^{(0)}(k)\right)^{2}\right] \cdot\left[\sum\left(b^{(0)}(k)\right)^{2}-\frac{1}{n} \sum\left(b^{(0)}(k)\right)^{2}\right]}}
$$

where $a^{(0)}(k)$ indicates the gas supply data by M1 at year $k$ and $b^{(0)}(k)$ indicates the gas supply data by M2 at year $k$ and $n$ is the number of forecast values. The maximum value of $R$ is 1 . The higher the value of $R$, the more similar a result can be obtained. The gas supply data by these two methods are compared and shown in Figure 5.

It is identified in Figure 7 that $R$ under the same IP scenarios are increasing with increasing price, indicating the increasing similarity of gas supply under a high price scenario. Under the low price scenario, the gas supply by M1 is obviously higher than the supply by M2. The peak production and URR with IP $=0.05 \mathrm{Mm}^{3}$ by M1 under the low price scenario are 2.8 billion $\mathrm{m}^{3}$ and $410.76 \mathrm{~m}^{3}$, respectively, while for M2 they are 2 billion $\mathrm{m}^{3}$ and $390.8 \mathrm{~m}^{3}$. Under the high price scenario, the gas supply by M1 is obviously lower than the supply by M2. The peak production and URR with $\mathrm{IP}=0.05 \mathrm{Mm}^{3}$ by M1 under the high price scenario are 3.8 billion $\mathrm{m}^{3}$ and $436.41 \mathrm{~m}^{3}$, respectively, while for $\mathrm{M} 2$ they are 9 billion $\mathrm{m}^{3}$ and $1563.2 \mathrm{~m}^{3}$. 


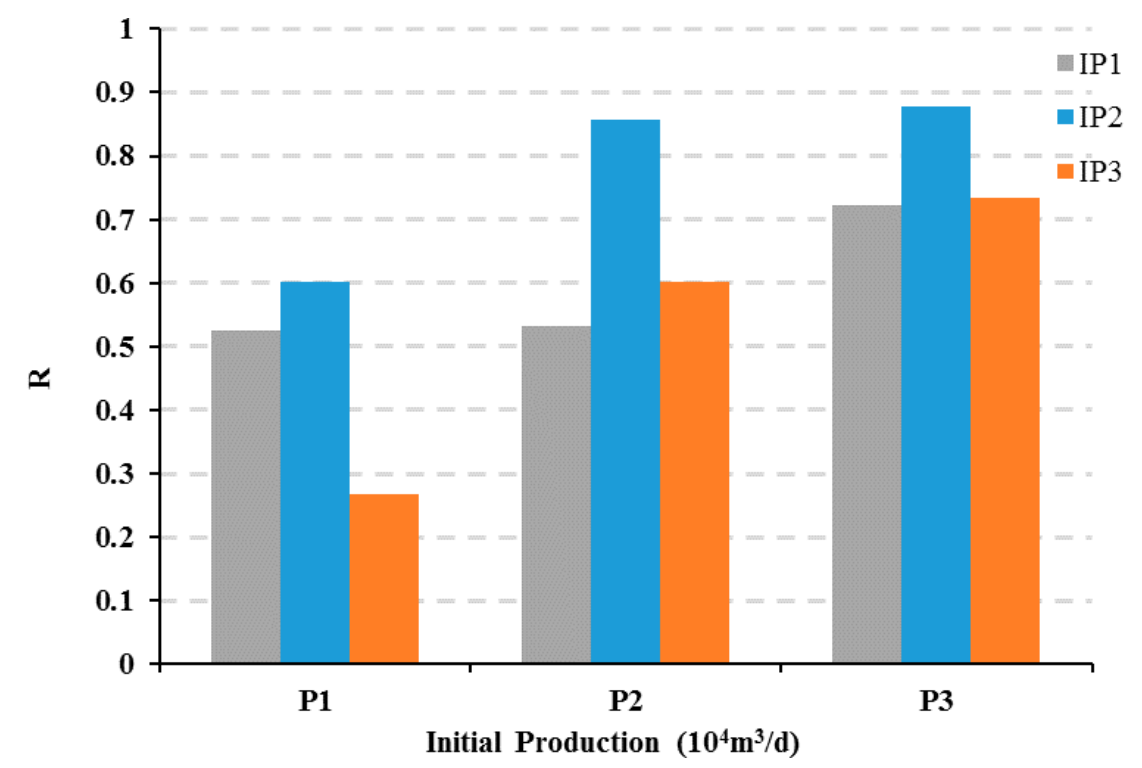

Figure 7. Correlation coefficient under different IP and price scenarios.

\subsection{Discussion}

According to the sensitivity analysis, M1 is sensitive to the IP profile, while M2 is sensitive to price changes. For M1, the peak production and URR will increase with the increasing IP, while peak time will increase with the increasing price, because operators will exaggerate the drilling plan gradually in an attempt to maximize revenue under the high price scenario. For M2, the peak production and URR will increase with the increasing price, while peak time will increase with the increasing IP under the same price scenario, which is determined by the M2 calculation. Since the URR is defined, the production rate will increase to the maximum rate with increasing IP.

Since M1 has been proved to be profitable with the NPV model, discounted cash flow analysis is also performed on shale gas by M2 to quantify the full range of prospect outcomes. Table 4 shows the $N P V$ for gas supply by M2 under different scenarios.

Table 4. NPV (10 ${ }^{8}$ yuan) for shale gas supply by M2.

\begin{tabular}{cccc}
\hline \multirow{2}{*}{ Price Scenario } & \multicolumn{3}{c}{ IP $\left(\mathbf{1 0}^{\mathbf{4}} \mathbf{~}^{\mathbf{3}} / \mathbf{d}\right)$} \\
\cline { 2 - 4 } & $\mathbf{5}$ & $\mathbf{1 0}$ & $\mathbf{1 5}$ \\
\hline Low & -1.2 & 2.4 & 5.4 \\
Reference & -2.1 & 1.1 & 3.4 \\
High & -5.5 & 1.5 & 2.8 \\
\hline
\end{tabular}

We can see that in the low price scenario, the NPV for gas supply with P1 by M2 is $-0.12,-0.21$ and -0.55 billion yuan. Thus, value is considered to be not created with low price, meaning the shale gas supply by M2 under the low price scenario is not suitable and only M1 can be used, while with increasing price, the NPV for gas supply with P2 and P3 by M2 are all above zero, so both of these methods can be employed to calculated the gas supply. Since operators will exaggerate the drilling plan gradually in an attempt to maximize revenue, the M2 is more suitable for relative high price calculations and is more feasible for its simplicity and accuracy. Thus the best estimation of gas supply for the Fuling shale gas field should be shown as in Figure 8. M1 is used for low price scenarios and M2 is used at reference and high price scenarios. 

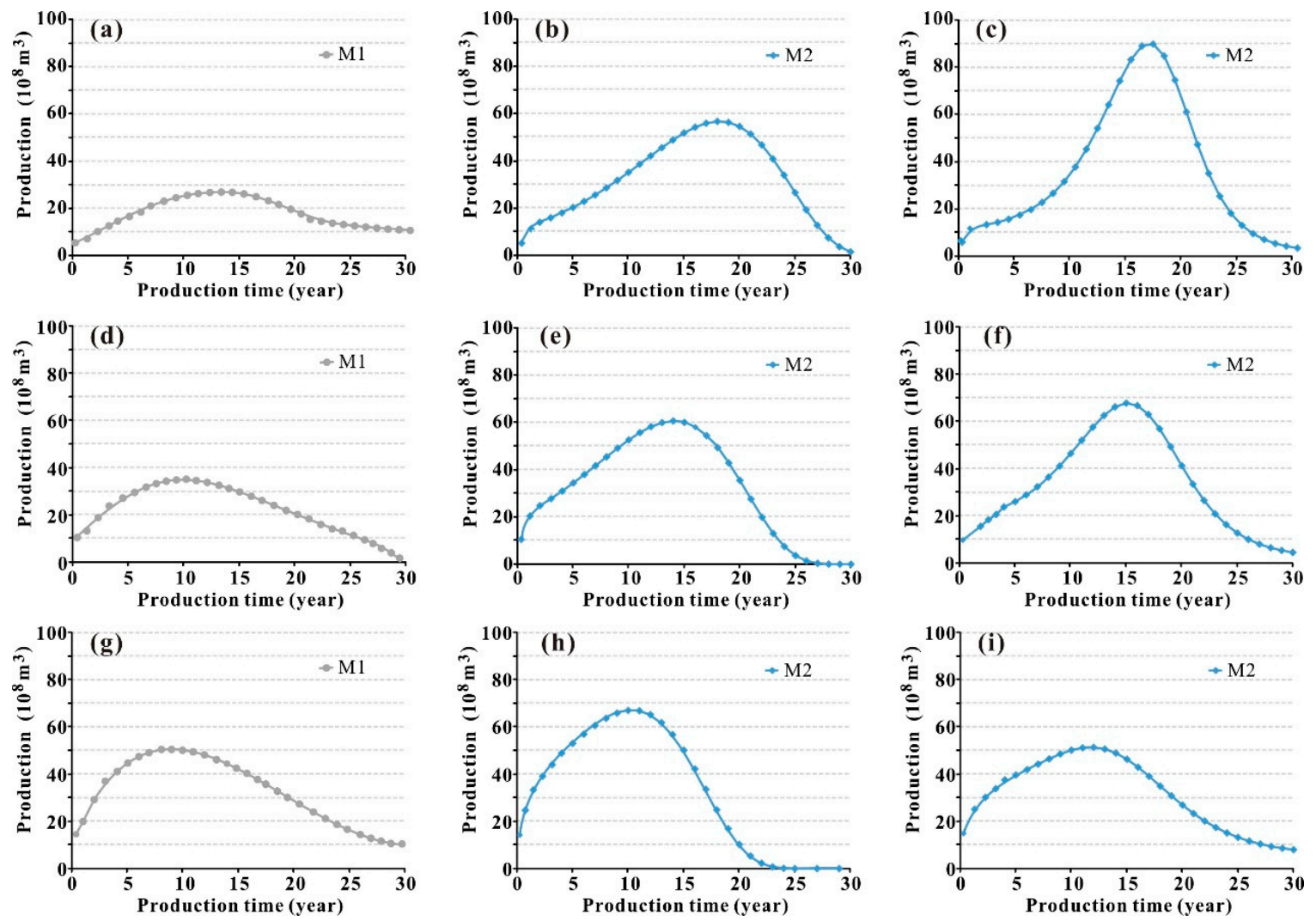

Figure 8. Best estimated gas supply under different IP and price scenarios. (a) IP1-P1; (b) IP1-P2; (c) IP1-P3; (d) IP2-P1; (e) IP2-P2; (f) IP2-P3; (g) IP3-P1; (h) IP3-P2; (i) IP3-P3.

\section{Conclusions}

In this study, our analysis focused on the assessment of two widely used methods for determining the shale gas supply in China and we hope to provide a quicker and comprehensive assessment method for the instruction of pipeline networks and gas plants in the next step. The Fuling shale field, the most perspective shale gas field in China, was chosen as a case study. Two different methods were chosen to derive the year-by-year gas supply: breakeven analysis and GeRs-DeMo. The breakeven analysis was based on the NPV model and cost and revenue for each exploration and exploitation stage were collected. In GeRs-DeMo method, the static model was used and different price scenarios was assumed according to the EIA's projection. RCGM was also used to assist the GeRs-DeMo method to calculate the year-by-year supply. We use a sensitivity analysis first to compare the influencing factors for each method. M1 is proved to be more sensitive to the IP profile, while M2 is more sensitive to the price scenarios. In addition, correlation coefficients were applied to characterize the differences and similarities between these two methods and we can make the following conclusions: (1) M1 is more suitable for low price scenarios since M2 is proven to be unprofitable; (2) both M2 and M1 can be employed for high price scenarios, while M2 is more feasible for its simplicity and accuracy in high price scenarios.

This assessment of shale gas supply methods is a certain case of the Fuling shale gas field. However, we should note that shale gas development in China is still in an initial stage, we still need careful and continuous investigations of changes in supply methods. With the development of new hydraulic fracture technology, the cost and single well production will change significantly. Furthermore, the gas price used in this study is based on the EIA's projection and real gas price may change in different ways. This research just provides a guideline for the method assessment and further more detailed work needs to be done to give more accurate gas supply predictions. 
Acknowledgments: We would like to thank all anonymous reviewers and editor for their work. This research was funded by the National Special Coal Resources Comprehensive Evaluation and Information System Construction (grant No. DD20160189), Energy Security Comprehensive Research and Dynamic Tracking Evaluation of Geological Mineral Investigation and Evaluation Project (grant No. DD20160084).

Author Contributions: Xiaoqian Guo and Anjian Wang have contributed in developing the ideas and the calculation of shale gas supply. All the authors are involved in preparing the manuscript.

Conflicts of Interest: The authors declare no conflict of interest.

\section{References}

1. "13th Five-Year Plan" for Development and Utilization of Natural Gas. Available online: http:/ / www.ndrc. gov.cn/zcfb / zcfbghwb/201701/W020170119368974618068.pdf (accessed on 13 September 2017).

2. Shale Oil and Shale Gas Resources Are Globally Abundant. Available online: https://www.eia.gov/ todayinenergy / detail.php?id=14431 (accessed on 13 September 2017).

3. “13th Five-Year Plan" for Development and Utilization of Shale Gas. Available online: http:/ / zfxxgk.nea. gov.cn/auto86/201609/t20160930_2306.htm?keywords= (accessed on 13 September 2017).

4. Zhang, Q.; Li, Z.; Wang, G.; Li, H. Study on the impacts of natural gas supply cost on gas flow and infrastructure deployment in China. Appl. Energy 2016, 162, 1385-1398. [CrossRef]

5. Chebeir, J.; Geraili, A.; Romagnoli, J. Development of Shale Gas Supply Chain Network under Market Uncertainties. Energies 2017, 10, 246. [CrossRef]

6. Dong, D.; Wang, Y.; Li, X.; Zou, C.; Guan, Q.; Zhang, C.; Huang, J.; Wang, S.; Wang, H.; Liu, H. Breakthrough and prospect of shale gas exploration and development in China. Nat. Gas Ind. B 2016, 3, 12-16. [CrossRef]

7. Zhang, M.J.; Tang, Q.Y.; Cao, C.H.; Lv, Z.; Zhang, T.; Zhang, D.; Li, A.; Du, L. Molecular and carbon isotopic variation in 3.5 years shale gas production from Longmaxi Formation in Sichuan Basin, China. Mar. Pet. Geol. 2017, 1, 1-11. [CrossRef]

8. Shaikh, F.; Ji, Q.; Shaikh, P.H.; Mirjat, N.H.; Uqaili, M.A. Forecasting China's natural gas demand based on optimised nonlinear grey models. Energy 2017, 140, 941-951. [CrossRef]

9. Wang, T.; Lin, B.Q. China's natural gas consumption and subsidies-From a sector perspective. Energy Policy 2014, 65, 541-551. [CrossRef]

10. Kaiser, M.J. Profitability Assessment of Haynesville Shale Gas Wells. Energy 2012, 38, 315-330. [CrossRef]

11. Innikova, S.; Gülen, G.; Browning, J.; Tinkwer, S.W. Profitability of shale gas drilling: A case study of the Fayetteville shale play. Energy 2014, 81, 382-393. [CrossRef]

12. Yuan, J.H.; Luo, D.K.; Feng, L.Y. A review of the technical and economic evaluation techniques for shale gas development. Appl. Energy 2015, 148, 49-65. [CrossRef]

13. Giovanni, F.S.; Campuzano, C.; Pineda, C. NPV risk simulation of an open pit gold mine project under the O'Hara cost model by using Gas. Int. J. Min. Sci. Technol. 2017, 27, 557-565. [CrossRef]

14. Hubbert, M.K. Techniques of Prediction as Applied to the Production of Oil and Gas; NBS special publication; National Bureau of Standards: Washington, DC, USA, 1982; pp. 16-141.

15. Oil and Gas Supply Module of the National Energy Modeling System. Available online: https://www.eia. gov/outlooks/aeo/nems/documentation/ogsm/pdf/m063(2014).pdf (accessed on 13 September 2017).

16. McGlade, C.; Speirs, J.; Sorrell, S. Unconventional Gas-A Review of Regional and Global Resource Estimates. Energy 2013, 55, 571-584. [CrossRef]

17. Liang, Y.X.; Dong, K.L. A Method for Calculating Economic Critical Depth of Shale Gas Resources in China Via Break-even Analysis. J. Nat. Gas Sci. Eng. 2014, 21, 1091-1098. [CrossRef]

18. Wang, K.; Feng, L.Y.; Wang, J.L.; Xiong, Y.; Tverberg, G.E. An Oil Production Forecast for China Considering Economic Limits. Energy 2016, 113, 586-596. [CrossRef]

19. Kahrl, F.; Hu, J.; Kwok, G.; Williams, J.H. Strategies for expanding natural gas-fired electricity generation in China: Economics and policy. Energy Strategy Rev. 2013, 2, 182-189. [CrossRef]

20. Yuan, J.H.; Luo, D.K.; Xia, L.Y.; Feng, L.Y. Policy Recommendations to Promote Shale Gas Development in China based on a Technical and Economic Evaluation. Energy Policy 2015, 85, 194-206. [CrossRef]

21. Zhou, X.H. Drilling \& Completion Techniques Used in Shale Gas Horizontal Wells in Jiaoshiba Block of Fuling Area. Pet. Drill. Tech. 2013, 41, 26-30. [CrossRef] 
22. Wang, Z.G. Breakthrough of Fuling Shale Gas Exploration and Development and its Inspiration. Oil Gas Geol. 2015, 36, 1-6.

23. Eshkalaka, M.O.; Aybar, U.; Sepehrnoori, K. An Economic Evaluation on the Re-fracturing Treatment of the U.S. Shale Gas Resources. In Proceedings of the SPE Eastern Regional Meeting, Charleston, WV, USA, 21-23 October 2014.

24. Notice of Shale Gas Exploitation Subside Policy. Available online: http://jjs.mof.gov.cn/zhengwuxinxi / zhengcefagui/201504/t20150427_1223392.html (accessed on 13 September 2017).

25. Fetkovich, M.J.; Vienot, M.E.; Bradley, M.D.; Kiesow, U.G. Decline curve analysis using type curves: Case histories. SPE Form. Eval. 1987, 2, 201-221. [CrossRef]

26. Alom, M.S.; Tamim, M.; Rahman, M.M. Decline curve analysis using rate normalized pseudo-cumulative function in a boundary dominated gas reservoir. J. Pet. Sci. Eng. 2017, 150, 30-42. [CrossRef]

27. Mohr, S.H.; Evans, G.M. Long-term Forecasting of Natural Gas Production. Energy Policy 2011, 39, 5550-5560. [CrossRef]

28. Wang, J.L.; Mohr, S.; Feng, L.Y.; Liu, H.H.; Tverberg, G.E. Analysis of Resource Potential for China's Unconventional Gas and Forecast for its Long-term Production Growth. Energy Policy 2016, 88, 389-401. [CrossRef]

29. Annual Energy Outlook 2017. Available online: https:/ / www.eia.gov/outlooks/aeo/pdf/0383\%282017\%29. pdf (accessed on 13 September 2017).

30. Wang, J.Z.; Jiang, H.Y.; Zhou, Q.P.; Wu, J.; Qin, S.S. China's Natural Gas Production and Consumption Analysis based on the Multicycle Hubbert Model and Rolling Grey Model. Renew. Sustain. Energy Rev. 2016, 53, 1149-1167. [CrossRef]

31. Ward, J.D.; Mohr, S.H.; Myers, B.R.; Nel, W.P. High estimates of supply constrained emissions scenarios for long-term climate risk assessment. Energy Policy 2012, 51, 598-604. [CrossRef]

32. Jiang, S.; Tang, X.L.; Long, S.X.; Maclannen, J.; Jiang, Z.L. Reservoir Quality, Gas Accumulation and Completion Quality Assessment of Zhilurian Longmaxi Marine Shale Gas Play in the Sichuan Basin, China. J. Nat. Gas Sci. Eng. 2017, 39, 203-215. [CrossRef]

33. Zou, C.N.; Dong, D.Z.; Wang, S.J. Geological Characteristics and Resource Potential of Shale Gas in China. Pet. Explor. Dev. 2010, 37, 641-653. [CrossRef]

34. Guo, X.F.; Hu, D.F.; Li, Y.P.; Wei, Z.H.; Wei, X.F.; Liu, Z.J. Geological factors controlling shale gas enrichment and high production in Fuling shale gas field. Pet. Explor. Dev. 2017, 44, 513-523. [CrossRef]

35. Shen, J.C.; Liu, Y.W. Application study on typical production decline curves of shale gas curves in Fuling Jiaoshiba block. Pet. Drill. Tech. 2016, 44, 88-94. [CrossRef]

36. Bai, Y.H.; Yang, H.; Chen, G.H.; Feng, Y.R.; Ding, Q.Q. Methods to Determine the Key Parameters of Typical Production Decline Curves of Shale Gas Reservoirs. Spec. Oil Gas Reserv. 2013, 22, 65-68. [CrossRef]

37. Mohr, S.H.; Wang, J.; Ellem, G.; Ward, J.; Giurco, D. Projection of world fossil fuels by country. Fuel 2015, 141, 120-135. [CrossRef]

38. William, J.H.; Brown, P.J. Evaluating Unconventional Resource Plays. In Proceedings of the SPE Annual Technical Conference and Exhibition, Dallas, TX, USA, 9-12 October 2005.

39. Zhu, N.P.; Zhao, Q.; Tian, L.X.; Zhang, Q. Cost Analysis and Development Strategies for China' Natural Gas Power Generation Industry under the Situation of Energy Price's Reformation. Energy Procedia 2016, 104, 203-208. [CrossRef]

(C) 2017 by the authors. Licensee MDPI, Basel, Switzerland. This article is an open access article distributed under the terms and conditions of the Creative Commons Attribution (CC BY) license (http://creativecommons.org/licenses/by/4.0/). 